\title{
Design and preparation of a novel colon-targeted tablet of hydrocortisone
}

\author{
Yachao Ren ${ }^{1}$, Lei Jiang ${ }^{1}$, Shuman Yang ${ }^{2}$, Sainan Gaoㄹ, Hui Yu${ }^{1}$, Jie Hu${ }^{1}$, Dandan Hu${ }^{1}$, Wenbin Mao \\ Haisheng Peng ${ }^{1 *}$, Yulong Zhou ${ }^{3 *}$
}

\begin{abstract}
${ }^{1}$ Harbin Medical University-Daqing, Daqing, China, ${ }^{2}$ Department of Environmental Health, Division of Epidemiology and Biostatistics, University of Cincinnati Medical Center, Cincinnati, Ohio, US, ${ }^{3}$ College of Animal Science and Technology, Heilongjiang Bayi Agricultural University, Daqing, China
\end{abstract}

\begin{abstract}
The objective of this research was to design a new colon-targeted drug delivery system based on chitosan. The properties of the films were studied to obtain useful information about the possible applications of composite films. The composite films were used in a bilayer system to investigate their feasibility as coating materials. Tensile strength, swelling degree, solubility, biodegradation degree, Fourier Transform Infrared Spectroscopy (FTIR), Differential Scanning Calorimetry (DSC), Scanning Electron Microscope (SEM) investigations showed that the composite film was formed when chitosan and gelatin were reacted jointly. The results showed that a 6:4 blend ratio was the optimal chitosan/gelatin blend ratio. In vitro drug release results indicated that the Eudragit- and chitosan/gelatin-bilayer coating system prevented drug release in simulated intestinal fluid (SIF) and simulated gastric fluid (SGF). However, the drug release from a bilayer-coated tablet in SCF increased over time, and the drug was almost completely released after $24 \mathrm{~h}$. Overall, colon-targeted drug delivery was achieved by using a chitosan/gelatin complex film and a multilayer coating system.
\end{abstract}

Uniterms: Chitosan/evaluation. Chistosan/evaluation/gelatin complex film. Drugs/administration. Drugs/ delivery system/Colon-targeting. Tablets/bilayer-coated.

\section{INTRODUCTION}

Colon-targeted drug delivery systems have been increasing interest for treating colonic diseases such as Crohn's disease, irritable bowel syndrome, and ulcerative colitis (Chourasia, Jain, 2004; Jain, Jain, 2008; Luo et al., 2011). Colon-targeted drug delivery increases efficacy and reduces side effects by delivering high drug concentrations topically at the colonic disease site. An ideal colonspecific drug delivery system should release most of the drug locally into the colon, and not into the stomach or small intestine (Rubinstein, 1995). Several strategies are currently being investigated for colon-specific delivery, including prodrugs (Dhaneshwar et al., 2007) and $\mathrm{pH}-$ sensitive (Yin et al., 2008; Vaghani, Pateland, Satish, 2012), time-dependent (Cui et al., 2007), and microflora-

\footnotetext{
*Correspondence: Y. Zhou. College of Animal Science and Technology. Heilongjiang Bayi Agricultural University, Province 163319, Daqing, China. E-mail: zhouyulong1980@163.com; H. Peng. Harbin Medical University-Daqing, Daqing, Heilongjiang, Province 163319, China. E-mail: fisher@163.com.
}

activated systems (Dev, Bali, Pathak, 2011; Yang, 2008). The $\mathrm{pH}$ of the gastrointestinal tract gradually increases as one moves down the gastrointestinal tract from the stomach $(\mathrm{pH} \mathrm{1.5-3)}$ to the terminal ileum $(\mathrm{pH}$ 7-8) (Gupta, Beckert, Price, 2001). pH-sensitive delivery systems takes advantage of polymeric materials that are insoluble in the low $\mathrm{pH}$ environment of the upper gastrointestinal tract, but dissolve at the higher, near neutral $\mathrm{pH}$ of the distal gut. Microflora-activated delivery systems are preferable and promising (Fan et al., 2009). The human colon is a dynamic and ecologically diverse system consisting of over 400 distinct bacterial species (Cummings, Macfarlane, 1991) that secrete a variety of enzymes (Guarner, Malagelada, 2003). The primary sources of nutrition for these bacteria are non-starch polysaccharides which are fermented during their transit through the colon and which are negligibly broken down in the stomach and small intestine (Englyst, Cummings, 1985). Currently, natural polysaccharides are extensively used for the development of solid dosage forms for the delivery of drugs to the colon (Nath, Nath, 2013). 
However, it was reported that a colon-specific delivery system which is based only on $\mathrm{pH}$-sensitive (Gupta, Beckert, Price, 2001) or microflora-activated systems have been reported as unreliable due to the inherent variability in $\mathrm{pH}$ or water swelling from the gastrointestinal tract. Fortunately, a bilayer system would serve as a unique drug delivery device that is compatible with conventional manufacturing methods. Similarly, multi-layered tablets have been developed to control drug delivery using a predefined release profile for different active ingredients. Therefore, we intend to design a new drug delivery system by a combining $\mathrm{pH}$-sensitive system with microflora-activated system.

Polysaccharides, which are metabolized by the colonic flora, have gained widely attention as potential colon targeting carriers for their non-toxic, hydrophilic, gel-forming, biodegradable, inexpensive, and abundant properties and they are available in various grades of varying properties. Chitosan, which is a high molecular weight natural polysaccharide, is completely biodegradable, non-toxic, low-cost, and has favorable gelation characteristics (Singla, Chawla, 2001). Chitosan cannot be digested in the upper gastrointestinal tract by human digestive enzymes (Bhattarai, Gunn, Zhang, 2010; Park et al., 2010). However, chitosan is prone to glycosidic hydrolysis by microbial enzymes in the colon (Chourasia, Jain, 2003; McConnell, Murdan, Basit, 2008; Muzzarelli, 2011). Furthermore, chitosan has been applied in colontargeted drug delivery systems in several forms such as capsules (Tozaki et al., 2002), matrices (Zambito, Di Colo, 2003), hydrogels (Zhang, Alsarra, Neau, 2002) and microspheres (Lorenzo-Lamosa et al., 1998). Therefore, the potential for chitosan to be used as a coating material is obvious. However, chitosan dissolves in the acidic solutions, i.e., a factor that would limit the applications of chitosan in colon-targeted drug delivery. Gelatin is a soluble protein compound obtained by partially hydrolyzing collagen. It has a number of applications in the biomedical field, such as in tissue engineering, wound dressing, drug delivery and gene therapy (Mano et al., 2007). Furthermore, gelatin films, which are thin, flexible and transparent biodegradable materials, are available for engineering food, packaging, drug delivery and other applications (Bergo, Sobral, 2007). Unfortunately, gelatin exhibits poor mechanical properties, limiting its possible applications. Blending is an easy way to improve the properties of polymer materials. Based on the above, a chitosan/gelatin complex film was prepared as an inner coat. Eudragit ${ }^{\circledR}$ L 100, anionic copolymers, dissociates above $\mathrm{pH} 6.0$ and was used as the outer coat.

The objective of this study was to develop a multi- unit delivery system of a model drug so that the majority of the drug release occurs in the colon in a sustained-release fashion. A schematic of the delivery system is shown in Figure 1. Hydrocortisone is more extensively used as a corticosteroid to cure inflammatory bowel disease. Hydrocortisone was used as a model drug in this study. Tablets were chosen for development because they are more economical and easier to industrialize.
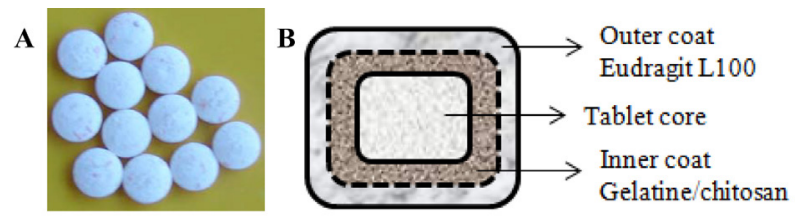

FIGURE 1 - Bilayer coated tablet. Bilayer coated tablet was prepared in this study (A); shematic of the bilayer coated tablet delivery system (not to scale) (B).

\section{MATERIAL AND METHODS}

\section{Material}

Hydrocortisone was purchased from Jinjin Pharmaceutical Co. Ltd. (Tianjin, China). The following excipients and chemicals were purchased from commercial sources and used as received: chitosan (deacetylation degree 96\%, Haidebei Co. Ltd., Shandong, China), microcrystalline cellulose (MCC, Huzhou Zhanwang Medical Company, Huzhou, China), Eudragit ${ }^{\circledR}$ L100 (Röhm Pharm, Darmstadt, Germany), triethylcitrate (TEC, Johnson Matthey company, USA), polyethylene glycol (PEG) 6000 (Pudong Chemical Co., Shanghai, China), talc and magnesium stearate (Shanghai Yunhong Pharmaceutical Excipients \& Technology Co. Ltd., Shanghai, China), lactose and gelatin (Beijing Aoboxing Biotechnology, Beijing, China), and pepsin, lipase and pectinase (Beijing Kebio Biotechnology, Beijing, China). The solvents were reagent grade; double distilled deionized water was used in all experiments.

\section{Film preparation}

Gelatin was dissolved in ultra-pure water, and chitosan was dissolved in a $2 \%$ acetic acid solution. The gelatin and chitosan solutions were mixed at different weight ratios (Table I) and PEG6000 was added as a plasticizer. Subsequently, the mixed solution was stirred for $15 \mathrm{~min}$ at room temperature. In this reaction, the gelatin and the chitosan array formed a complex. Subsequently, the mixtures were cast onto silanized glass Petri dishes and dried at room temperature for 5-7 days. After drying, the 
gelatin/chitosan films were removed from the Petri dishes and stored in desiccators at room temperature.

TABLE I - Formulation design of film

\begin{tabular}{lcc}
\hline $\begin{array}{l}\text { Formulation } \\
\text { No. (FN) }\end{array}$ & Composition & Weight Rate \\
\hline 1 & Gelatin/chitosan/PEG & $10: 0: 1$ \\
2 & Gelatin/chitosan/PEG & $9: 1: 1$ \\
3 & Gelatin/chitosan/PEG & $8: 2: 1$ \\
4 & Gelatin/chitosan/PEG & $7: 3: 1$ \\
5 & Gelatin/chitosan/PEG & $6: 4: 1$ \\
6 & Gelatin/chitosan/PEG & $5: 5: 1$ \\
7 & Gelatin/chitosan/PEG & $4: 6: 1$ \\
8 & Gelatin/chitosan/PEG & $3: 7: 1$ \\
9 & Gelatin/chitosan/PEG & $2: 8: 1$ \\
10 & Gelatin/chitosan/PEG & $1: 9: 1$ \\
11 & Gelatin/chitosan/PEG & $0: 10: 1$ \\
\hline
\end{tabular}

\section{Preparation of the simulated gastric/intestinal fluid}

\section{Preparation of the simulated gastric/intestinal fluid with enzyme}

According to the prepared method of the simulated gastric/intestinal fluid in the Chinese Pharmacopoeia 2010, a simulated gastric fluid (SGF) was prepared comprising an aqueous solution containing $12,000 \mathrm{U} / \mathrm{L}$ pepsin adjusted to $\mathrm{pH} 1.5$ using $0.1 \mathrm{M} \mathrm{HCl}$. A simulated intestinal fluid (SIF) was prepared comprising an 8400 $\mathrm{U} / \mathrm{L}$ lipase solution in a phosphate buffer ( $\mathrm{pH}$ 7.4). A simulated colonic fluid (SCF) was prepared comprising a $6 \mathrm{~g} / \mathrm{L}$ pectinase solution in a phosphate buffer $(\mathrm{pH} 6.8)$.

\section{Preparation of the simulated colonic fluid with rat colonic medium (RCM)}

The extracellular enzymes released from the microflora in rat colonic contents had more profound degradation effects on chitosan than their membrane enzymes (Zhang, Alsarra, Neau, 2002). Therefore, rat colonic medium was prepared. Male Wistar rats (200-300 g) were lightly anesthetized using ether, and sacrificed by decapitation. Their caeca were exteriorized, cauterized at both ends ( $2.0 \mathrm{~cm}$ apart), cut loose, and immediately removed from the rat body. The formed cecal bag was opened, and its contents were weighed, pooled, and suspended in two volumes of cold bicarbonate-buffered saline to give a final cecal dilution of $33 \%(\mathrm{w} / \mathrm{v})$. The suspension was filtered through a 400 mesh grit twice to remove any debris. The supernatant was then centrifuged at $15,000 \mathrm{x} g$ for $30 \mathrm{~min}$ to obtain a clear supernatant containing the extracellular enzymes (Zhang, Alsarra, Neau, 2002). The animal study protocol was approved by the Animal Care and Use Committee of Harbin Medical University.

\section{Film characteristics}

\section{Appearance}

The surface conditions and color of the gelatin/ chitosan films were observed.

\section{Thickness}

The thickness of the gelatin/chitosan films was determined with a micrometer, and the average value of 10 measurements taken at random points was reported.

\section{Tensile strength measurement}

The gelatin/chitosan films were cut into rectangular samples. Four tests were performed with each film at room temperature using an electronic universal testing machine BLD 200S (Jinan, China). The characteristic parameters of the rectangular samples included a $40-\mathrm{mm}$ gauge length and a $10-\mathrm{mm}$ width. Average values from at least three measurements were reported. The tensile strength (TS) was calculated using the following expression:

$$
\delta=\mathrm{P} /(\mathrm{b} \bullet \mathrm{d})
$$

where $\delta$ is the tensile strength, $\mathrm{P}$ is the maximal tension needed to break the film, $\mathrm{b}$ is the width of the film and $\mathrm{d}$ is the thickness of the film.

\section{Swelling of film}

The degree of swelling was determined gravimetrically. Films $20 \mathrm{~mm}$ long and $20 \mathrm{~mm}$ wide were put into SGF, SIF and SCF without enzymes to swell at the experimental temperature. The samples were removed at regular intervals from the buffers, blotted with filter paper, weighed and replaced in the same immersion bath. This process was repeated until a swelling equilibrium was reached. The swelling degree was defined as the weight of water imbibed by the sample per unit weight of film. Each film was analyzed three times. The equilibrium swelling degree $\mathrm{Q}_{\infty}$ was calculated in grams of water per gram of film using the following expression:

$$
\mathrm{Q}_{\infty}(\%)=\left(\mathrm{m}_{\infty}-\mathrm{m}_{0}\right) \times 100 / \mathrm{m}_{0}
$$

where $m_{0}$ is the initial weight of the dried film, and $m_{\infty}$ is the weight of film at swelling equilibrium. 


\section{Solubility of film}

Dried films $(\mathrm{n}=3)$ were weighed $\left(\mathrm{W}_{1}\right)$ and immersed in SGF, SIF and SCF without enzyme for $24 \mathrm{~h}$, dried in vacuo overnight, and weighed again $\left(\mathrm{W}_{2}\right)$. The solubility of each sample was determined three times. Solubility (S) was calculated using Eq. (3):

$$
\mathrm{S}(\%)=\left(\mathrm{W}_{1-} \mathrm{W}_{2}\right) \times 100 / \mathrm{W}_{1}
$$

\section{Fourier transform infrared spectroscopy (FTIR)}

The films were cut into small pieces and $\mathrm{KBr}$ discs were prepared. Infrared spectra were recorded on an $8400 \mathrm{~S}$ FTIR spectrometer (Shimadzu, Japan) in the 4000-400 $\mathrm{cm}^{-1}$ region.

\section{Differential Scanning Calorimetry (DSC)}

DSC assays of gelatin/chitosan/PEG mixtures and gelatin/chitosan films were performed by using $a$ DZ3335 DSC (Nanjingdazhan, China) instrument. $A$ sample (5mg) was scanned in an aluminum pan over a temperature range between $35^{\circ} \mathrm{C}$ to $340^{\circ} \mathrm{C}$ under nitrogen at a scanning rate of $5^{\circ} \mathrm{C} / \mathrm{min}$. All scans were performed in triplicate.

\section{Scanning electron microscope (SEM) analysis}

Surface morphologies were examined by SEM using a S3400N scanning microscope from Hitachi Ltd. Co. (Tokyo, Japan) at an accelerating voltage of $15 \mathrm{kV}$. Samples were mounted on metal stubs and coated with gold by ion sputtering instrument E-1010.

\section{Characterization of biodegradation}

The gelatin/chitosan films with thicknesses averaging 0.6-0.8 $\mathrm{mm}$ were cut into $2 \mathrm{~cm} \times 2 \mathrm{~cm}$ pieces. The film samples were degraded in $20 \mathrm{ml} \mathrm{SGF} \mathrm{(2} \mathrm{h),} \mathrm{SIF}$ (24 h), SCF (24 h) or RCM (24 h). Each sample was tested three times. The degradation degree $\left(D_{t}\right)$ at time $t$ was calculated using the following expression:

$$
\mathrm{D}_{\mathrm{t}}=\left(\mathrm{m}_{\mathrm{t}}-\mathrm{m}_{0}\right) / \mathrm{m}_{0}
$$

where $\mathrm{m}_{0}$ is the initial weight of the dried film (at $\mathrm{t}=0$ ), and $m_{t}$ is the weight after a time $t$.

\section{Preparation and evaluation of colon-targeted tablets}

\section{Core tablet preparation}

The formulation of prototypical core tablets containing $10 \mathrm{mg}$ hydrocortisone were prepared using a wet granulation technique. The tablets contained $46 \%$ MCC, $46 \%$ lactose, $2 \%$ PVPP and $1 \%$ magnesium stearate. The drug and excipients were mixed. The dry blend was granulated with $3 \%$ aqueous $\mathrm{PVPK}_{30}$ solution as the binding solution, passed through a no. 16 mesh, and dried at $55^{\circ} \mathrm{C}$ on a tray drier. The dried granules were passed through a no. 20 mesh before they were blended with $1.0 \%(\mathrm{w} / \mathrm{w})$ magnesium stearate and compressed using an 8-mm punch on a single punch tablet press (DP30A, Beijing Gylongli Sci. \& Tech. Co., Ltd., China). Core tablets were evaluated based on friability, hardness and disintegration.

\section{Preparation of coating tablets}

Three layers of polymeric coatings were applied to all core tablets in the following order: HPMC, gelatin/ chitosan and Eudragit L100. The HPMC coat formulation was prepared by dissolving $2 \%(\mathrm{w} / \mathrm{v}) \mathrm{HPMC}$ in $80 \%$ ethanol HPMC, the gelatin/chitosan coat formulation was gelatin $(2 \%, \mathrm{w} / \mathrm{v})$, chitosan $(3 \%, \mathrm{w} / \mathrm{v})$, PEG $(0.5 \%, \mathrm{w} / \mathrm{v})$, and $3 \%$ talc $(3 \%, \mathrm{w} / \mathrm{v})$ in $2 \%$ acetic acid solution, and the Eudragit L100 coat formulation was Eudragit L100 (6\%, $\mathrm{w} / \mathrm{v})$, triethyl citrate $(1 \%, \mathrm{w} / \mathrm{v})$, and talc $(3 \%, \mathrm{w} / \mathrm{v})$ in an ethyl alcohol/water mixture(96/4). The coating weight gains for the HPMC, Eudragit L100 and gelatin/chitosan formulations were $2 \%, 4 \%$ and $20 \%$, respectively.

\section{In vitro dissolution testing}

Hydrocortisone release profiles from uncoated, gelatin/chitosan-coated, Eudragit-coated and bilayercoated tablets were assessed by three-step dissolution experiments (Liu et al., 2007), which were carried out in RC-6 dissolution tester (Tian Jin Optical Instrument Factory, China) to simulate the GIT under physiological conditions (250 ml per vessel): $2 \mathrm{~h}$ in SGF, $4 \mathrm{~h}$ in SIF and finally, $24 \mathrm{~h}$ in SCF. The stirring rates in SGF, SIF and SCF were 20, 20, and $5 \mathrm{rpm}$, respectively, and the temperature was maintained at $37^{\circ} \mathrm{C}$. Aliquots of the dissolution medium were withdrawn at predetermined times and replaced with the same volume of corresponding release medium to maintain a consistent volume. Each test was performed in triplicate and the release of hydrocortisone was monitored at $243 \mathrm{~nm}$ (UV $2000 \mathrm{UV}$ vis spectrophotometer).

\section{Stability studies}

The bilayer-coated tablets were stored in a highdensity polyethylene plastic bottle with silica gel. A stability study of the bilayer-coated tablet was carried out according to ICH guidelines at $40 \pm 2{ }^{\circ} \mathrm{C} / 75 \% \pm 5 \% \mathrm{RH}$ (Nagendra, Roopa, Gurinder, 2014). Physical attributes of the tablets, i.e., appearance, percentage drug content and dissolution profiles were tested over a period of 6 months. 


\section{Data analysis}

The Rank Sum Ratio (RSR) method was used to evaluate the effect of the formulation composition on films using seven indices: tensile strength (TS), swelling degrees (Q) in SIF and SCF without enzyme, solubility (S) in SIF and SCF without enzyme, and biodegradation degree (D) in SIF and in SCF. High TS, Q in SCF without enzyme (QC), S in SCF without enzyme (SC) and D in SCF (DC), and low Q in SIF (QI), S in SIF without enzyme (SI) and $\mathrm{D}$ in SIF (DI) facilitate better film performance. Therefore, TS, QC, SC and DC were the high optimization indices. QI, SI and DI were the low optimization indices. The best film was identified by Eq. (5):

$$
R_{n} R_{n}=\frac{1}{7 \times 11} \sum_{j=1}^{7} R_{n j}
$$

where $n$ represents the line, $j$ represents the array and $R_{n j}$ is the rank of $\mathrm{n}$ among the $\mathrm{j}$ indices.

SPSS11.5 software was used for all statistical analyses. A value of $\mathrm{P}<0.05$ was considered significant.

\section{RESULTS AND DISCUSSION}

\section{Film characteristics}

\section{Film appearance and thickness}

The gelatin/chitosan films were homogeneous, transparent and slightly brittle. The color of the films deepened as the chitosan content increased.

The average thicknesses of the films are listed in Table II. The thickness of the films significantly increased from 0.058 to $0.079 \mathrm{~mm}$ when the chitosan content

TABLE II - Physicochemical properties of the gelatin/chitosan films

\begin{tabular}{lcc}
\hline FN & Average thickness $(\mathbf{m m})$ & Tensile strength $(\mathbf{M P a})$ \\
\hline 1 & $0.058 \pm 0.0031$ & $29.8 \pm 2.1$ \\
2 & $0.060 \pm 0.0075$ & $31.2 \pm 6.5$ \\
3 & $0.061 \pm 0.0024$ & $31.5 \pm 4.9$ \\
4 & $0.064 \pm 0.0069$ & $33.3 \pm 5.2$ \\
5 & $0.065 \pm 0.0038$ & $34.9 \pm 3.6$ \\
6 & $0.067 \pm 0.0052$ & $36.5 \pm 6.5$ \\
7 & $0.069 \pm 0.0047$ & $33.5 \pm 4.1$ \\
8 & $0.072 \pm 0.0091$ & $32.5 \pm 5.3$ \\
9 & $0.073 \pm 0.0064$ & $30.1 \pm 3.9$ \\
10 & $0.075 \pm 0.0082$ & $23.7 \pm 4.7$ \\
11 & $0.079 \pm 0.0025$ & $17.4 \pm 2.8$ \\
\hline
\end{tabular}

increased. The film thickness was likely to be dependent on the film nature and composition. This result was similar to the resulst reported by Sebti et al. (2007) and Di Pierro et al. (2006) who showed possible relationships between film thickness and film-forming polymer content and nature.

\section{Tensile strength measurement}

The tensile strengths (TS) of the gelatin/chitosan films are presented in Table II. The TS of the composite membrane increased compared with the chitosan film, and the mechanical behavior of the composite film improved due to the added gelatin. A few studies have suggested that films formed from mixtures likely improved their physicochemical properties (Di Pierro et al., 2006; Prodpran, Benjakul, Artharn, 2007). Chitosan contains more functional groups such as hydroxyls, amines and amides, whereas gelatin has more carboxyl and amino groups (Celasco et al., 2008). These groups may form electrostatic and hydrogen bonding interactions. Furthermore, when the gelatin and chitosan films were prepared, the non-covalent interactions, such as hydrogen bonding and hydrophobic interactions, likely formed between the gelatin and chitosan molecules (Cao, $\mathrm{Fu}, \mathrm{He}$, 2007). Therefore, the tensile strength of the composite film increased due to the non-covalent interactions between gelatin and chitosan. However, when the chitosan content continued to increased up to and beyond a $60 \%$ mass fraction, the TS of the composite film decreased. There may not have been enough gelatin to form the noncovalent interactions with chitosan.

\section{Influence of the simulated gastrointestinal tract environment on the complex film}

The swelling behavior, solubility and the in vitro degradation of the films are reported in Table III. The $\mathrm{Q}_{\infty}$ values revealed that all the films had water retention capabilities. The $\mathrm{Q}_{\infty}$ values of the blended films depended on the chitosan/gelatin blend ratios and the physical structure of the films. The composite films had improved the mechanical strength, thermal stability, and swelling capability of films. The $\mathrm{Q}_{\infty}$ slightly decreased with the chitosan content increasing in SIF and SCF; $\mathrm{Q}_{\infty}$ was smaller when the chitosan content was $50 \%-80 \%$. These results agreed with studies that reported composite films improved mechanical strength (McConnell, Murdan, Basit, 2008) and swelling capability of films (Rueda, Secall, Bayer, 1999).

The ability to regulate the solubility of biodegradable films presents a number of potential 
advantages in biomaterials. Therefore, the solubility of the films at gastrointestinal $\mathrm{pH}$ was studied. As shown in Table III, the solubility of the blended films in SIF and SCF decreased rapidly as the chitosan content increased. The solubility of the chitosan film was $14 \%$ and $18 \%$ in SIF and SCF when treated for $24 \mathrm{~h}$ at room temperature, respectively. It reveals that the blend ratio had a significant effect on the solubility of the film. This may be because gelatin is a water-soluble polymer and because chitosan is insoluble in pure water at neutral $\mathrm{pH}$ but soluble in acidic solutions.

The films were easy to prepare by casting or spraying methods. The properties of the composite films were evaluated and these films are experimentally economical and statistically efficient (Pinotti et al., 2007). The degradation behaviors of the chitosan/ gelatin complexes were investigated as films. In vitro degradation tests of the chitosan/gelatin films were conducted by immersing the films in the SGF, SIF and SCF. The effect of chitosan content on degradation is presented in Table III. The biodegradability of the composite film in SIF rapidly decreased with the increasing chitosan content. The biodegradability of the blended film in SCF also declined when the chitosan content increased, but the trend was not obvious when the blended film ratio was $1: 1$. This phenomenon was in line with studies that reported that chitosan is susceptible to glycosidic hydrolysis by microbial enzymes in the colon (Chourasia, Jain, 2003; McConnell, Murdan, Basit, 2008; Vargas et al., 2009).

\section{Results of the RSR Test to Evaluate Preparations with Different Compositions}

Because all indices were not simply positively correlated or negatively correlated, the RSR method was used to evaluate all these films. Data of RSR test was indicated in Table III. From Table I and Table III, we learn that FN5, that is the chitosan/gelatin/PEG $(6: 4: 1, \mathrm{w} / \mathrm{w} / \mathrm{w})$ film, was relatively optimal.

\section{Evaluation of the optimal film}

\section{FTIR}

The changes in the structure of chitosan film were examined by FTIR spectroscopy as shown in Figure 2. The FTIR spectra of the gelatin, gelatin/chitosan and chitosan films showed a broad peak between 2800 and $3500 \mathrm{~cm}^{-1}$, attributed to the stretching of $\mathrm{OH}$ bonds and to the hydrogen bridges in films with PEG. The gelatin/ chitosan films had wider peaks in that region, possibly due to strong interactions between gelatin and chitosan. This result agreed with those reported by Rueda, Secall, Bayer (1999); Mansur, Oréfice, Mansur (2004) who observed a broadened peak around $3400 \mathrm{~cm}^{-1}$.

\section{DSC}

Cao's reports indicated that the non-covalent interactions were formed between the gelatin and chitosan molecules when the film was formed (Cao, $\mathrm{Fu}, \mathrm{He}, 2007$ ). To investigate whether each ingredient of the complex

TABLE III - Results of the RSR test

\begin{tabular}{|c|c|c|c|c|c|c|c|c|c|c|c|c|c|c|c|}
\hline \multirow{2}{*}{ FN } & \multicolumn{2}{|c|}{ TS(MPa) } & \multicolumn{2}{|c|}{ QI (\%) } & \multicolumn{2}{|c|}{ QC (\%) } & \multicolumn{2}{|c|}{ SI (\%) } & \multicolumn{2}{|c|}{ SC (\%) } & \multicolumn{2}{|c|}{ DI (\%) } & \multicolumn{2}{|c|}{ DC (\%) } & \multirow{2}{*}{ RSR } \\
\hline & $\mathbf{X}_{1}$ & $\mathrm{R}_{1}$ & $X_{2}$ & $\mathbf{R}_{2}$ & $\mathbf{X}_{3}$ & $\mathbf{R}_{3}$ & $\mathbf{X}_{4}$ & $\mathbf{R}_{4}$ & $X_{5}$ & $\mathbf{R}_{5}$ & $X_{6}$ & $\mathbf{R}_{6}$ & $\mathbf{X}_{7}$ & $\mathbf{R}_{7}$ & \\
\hline 1 & 29.8 & 3 & - & 1 & - & 1 & 90 & 1 & 91 & 11 & 93 & 1 & 94 & 11 & 0.34 \\
\hline 2 & 31.2 & 5 & - & 1 & - & 1 & 80 & 2 & 86 & 10 & 82 & 2 & 87 & 10 & 0.34 \\
\hline 3 & 31.5 & 6 & 272 & 3 & 339 & 11 & 58 & 3 & 83 & 9 & 66 & 3 & 85 & 9 & 0.49 \\
\hline 4 & 33.3 & 8 & 204 & 4 & 279 & 10 & 42 & 4 & 70 & 8 & 48 & 4 & 72 & 8 & 0.49 \\
\hline 5 & 34.9 & 10 & 176 & 5 & 253 & 9 & 30 & 5 & 36 & 7 & 45 & 5 & 55 & 7 & 0.49 \\
\hline 6 & 36.5 & 11 & 102 & 10 & 157 & 6 & 24 & 6 & 25 & 5 & 39 & 7 & 48 & 4 & 0.49 \\
\hline 7 & 33.5 & 9 & 100 & 11 & 164 & 7 & 24 & 6 & 29 & 6 & 44 & 6 & 52 & 6 & 0.55 \\
\hline 8 & 32.5 & 7 & 114 & 6 & 168 & 8 & 23 & 8 & 24 & 4 & 30 & 9 & 49 & 5 & 0.52 \\
\hline 9 & 30.1 & 4 & 104 & 9 & 113 & 3 & 20 & 10 & 21 & 3 & 31 & 8 & 36 & 3 & 0.47 \\
\hline 10 & 23.7 & 2 & 107 & 7 & 117 & 4 & 21 & 9 & 19 & 2 & 25 & 10 & 31 & 1 & 0.43 \\
\hline 11 & 17.4 & 1 & 105 & 8 & 119 & 5 & 14 & 11 & 18 & 1 & 17 & 11 & 32 & 2 & 0.49 \\
\hline
\end{tabular}

$\mathrm{X}_{1}-\mathrm{X}_{7}$ are the values for the TS, QI, QC, SI, SC, DI, and DC, respectively. $\mathrm{R}_{1}-\mathrm{R}_{7}$ are the ranks of the TS, QI, QC, SI, SC, DI, and DC, respectively. 


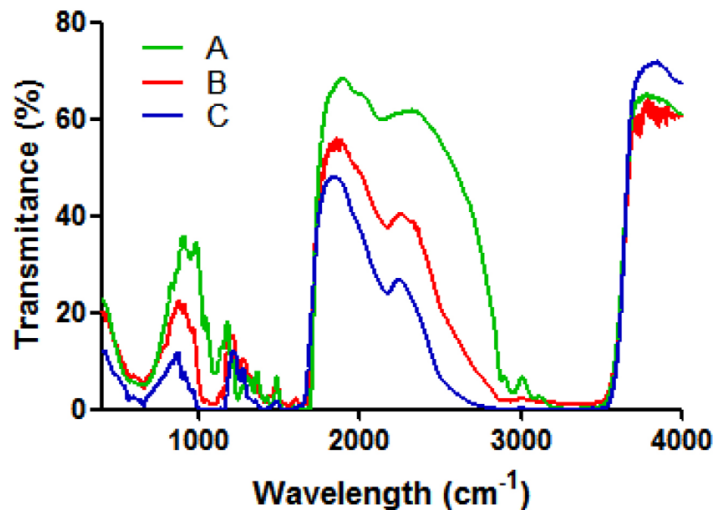

FIGURE 2 - FTIR spectra of gelatin (A), gelatin/chitosan (B) and chitosan (C) films.

film interacted with each other, the DSCs of the gelatin, chitosan, PEG, gelatin/chitosan/PEG mixture and gelatin/ chitosan films were performed. As shown in Figure 3, the gelatin/chitosan/PEG powder mixture had an endothermic transition at approximately $200{ }^{\circ} \mathrm{C}$. However, the complex film did not show any endothermic or exothermic transition. As expected, these results suggested that interactions were produced among gelatin, chitosan and PEG when the film was formed, which was similar to the resulst reported by Sebti et al. (2007) and Cao, Fu, He (2007).

\section{SEM}

Scanning electron microscopy images of the gelatin, chitosan and gelatin/chitosan films are shown in Figure 4. Figure 4 A shows that the structure of the gelatin film was homogeneous, convex and continuous. The chitosan and gelatin/chitosan films were smooth and had compact structures, as shown in Figures $4 \mathrm{~B}$ and C. These observations agree with reports that the surface of chitosan films presents as a smooth, continuous and compact structure (Ghaffari, 2007; Yu et al., 2011). This indicates that the presence of gelatin hardly caused structural changes in the chitosan film when the chitosan/ gelatin blend ratio was $6: 4$.

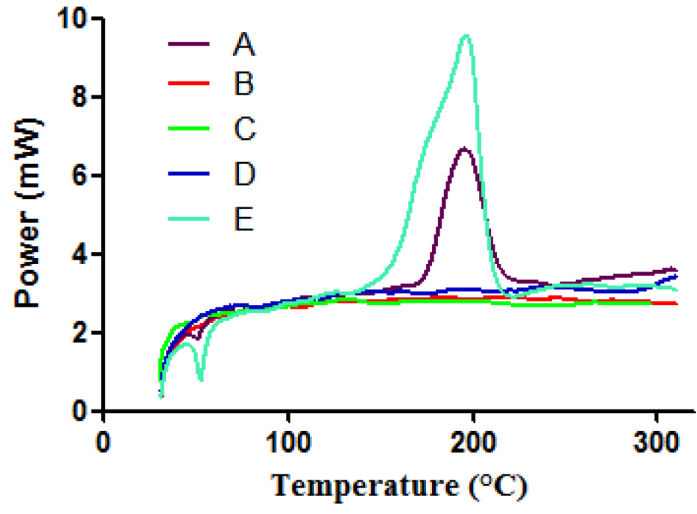

FIGURE 3 - DSC curves of gelatin/chitosan/PEG mixture (A) gelatin/chitosan films (B), chitosan (C), gelatin (D) and PEG (E).

\section{Biodegradation of the optimal film in rat colonic} medium

The study of the degradation rate of the optimal film was conducted by immersing the film samples in rat colonic medium. The degradation profile of the optimal film is shown in Fig. 5. The biodegradability of the optimal film in rat colonic medium increased sharply to $65 \%$ after $24 \mathrm{~h}$. Under the same conditions, the degradation was only $32 \%$ in SCF. A significant difference between the weight losses of the optimal film in rat colonic medium and in SCF was observed. Rat cecal contents contained more enzymes secreted by a variety of bacterial species. Chitosan is easily degraded by glycosidic hydrolysis by microbial enzymes in the colon (Finegold, 1977; Gamelin et al., 1998; Yang, 2008). Salyers, Leedle (1983) demonstrated that more than one bacterial enzyme was involved in the digestion of polysaccharides. Thus, the rat bacterial enzymes were more effective in degrading chitosan film than pectinase enzyme, promoting the degradation of the film by bacterial enzymes.

\section{Attributes of core tablets}

The average weight of the uncoated core tablets was $200 \mathrm{mg}$. The hardness of the tablets was $4.6 \mathrm{~kg} /$
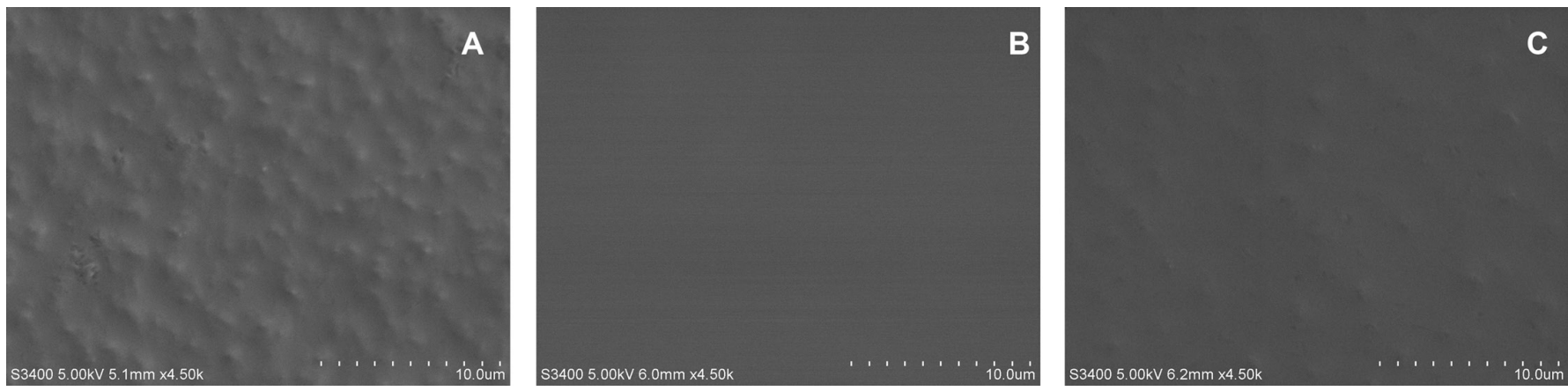

FIGURE 4 - SEM images of the surfaces of gelatin (A); chitosan (B) and gelatin/chitosan (C) films. 


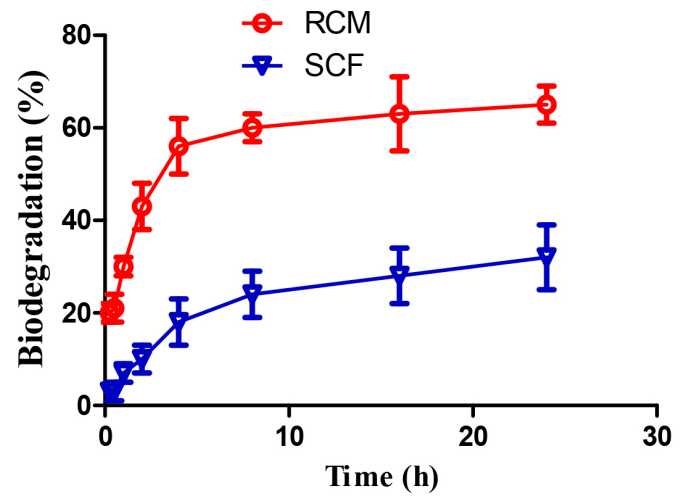

FIGURE 5 - Biodegradation of the optimal film in $S C F$ and RCM.

$\mathrm{cm}^{2}$, and their friability ranged from $0.08 \%$ to $0.20 \%$ $(\mathrm{w} / \mathrm{w})$. The uncoated tablets were prepared using $1 \%$ $\operatorname{PVPP}(\mathrm{w} / \mathrm{w})$.

\section{In vitro drug release studies in simulated gastrointestinal fluids}

The in vitro release studies were performed in medium at different $\mathrm{pHs}$ at $37^{\circ} \mathrm{C} \pm 0.5^{\circ} \mathrm{C}$. As was shown in Fig. $6 \mathrm{~A}$, the uncoated and gelatin/chitosan-coated tablets showed immediate release characteristics in SGF, compared with the Eudragit and bilayer-coated tablets. However, the Eudragit coating prevented drug release in $\mathrm{SGF}$ at $\mathrm{pH} 1.2$ but allowed for rapid and complete drug release in SIF when the $\mathrm{pH}$ was raised to $\mathrm{pH}$ 7.4. There was no measurable drug release for bilayer-coated tablets up to $2 \mathrm{~h}$ in SGF (pH 1.2). In SIF at $\mathrm{pH} 7.4$, the drug release was negligible $(<5 \%)$ up to $4 \mathrm{~h}$. Thus, the bilayer coating prevented drug release in SGF and SIF. After dissolution, the bilayer-coated tablet was tested in SGF for $2 \mathrm{~h}$ and SIF for $4 \mathrm{~h}$, and its dissolution was further detected in SCF. The drug release in the bilayer-coated tablet in SCF increased over time, and the drug was almost completely released after $24 \mathrm{~h}$ (Fig.6 B). Therefore, the Eudragit and chitosan/gelatin-coated tablets would likely resist release in the upper GI tract and thereby, prevent drug release at non-targeted sites.

\section{Stability studies}

Accelerated stability studies were carried out for a duration of 6 months as per ICH guidelines. As shown in Table IV, the formulation was stable according to the evaluation of the formulation for physical appearance, drug content and drug release profile.
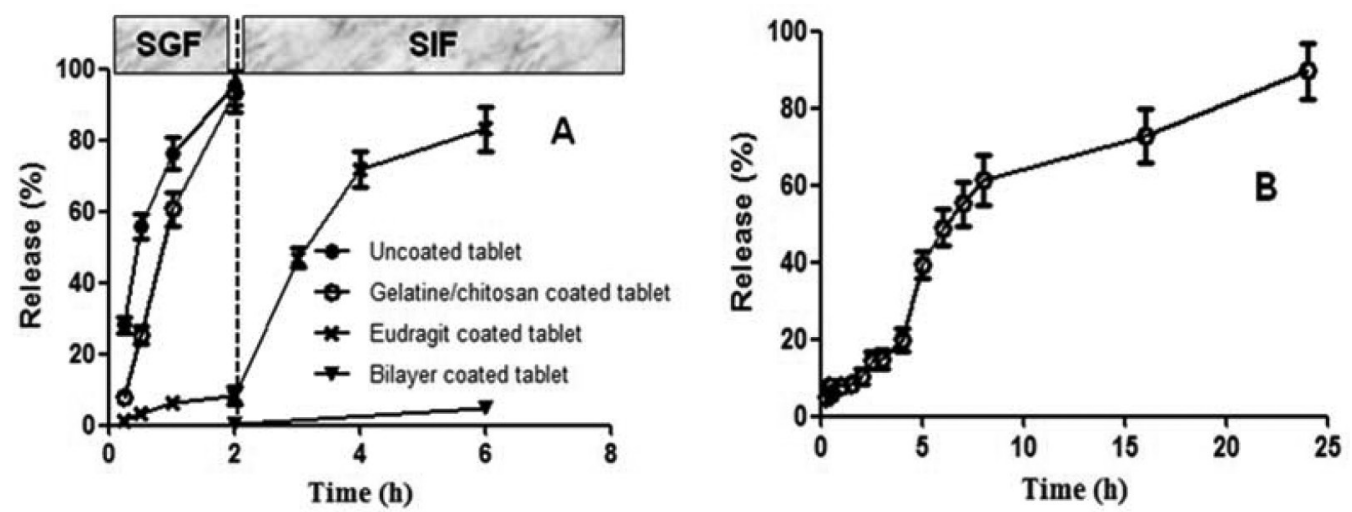

FIGURE 6 - Dissolution profiles of uncoated tablet and gelatin/chitosan, Eudragit and bilayer-coated tablets in SGF and SIF (A), and bilayer-coated tablet in SCF after it was tested in SGF for $2 \mathrm{~h}$ and SIF for $4 \mathrm{~h}(\mathrm{~B})$.

TABLE IV - Physicochemical properties of bilayer-coated tablet during 6-month accelerated stability studies

\begin{tabular}{lccccc}
\hline Time (months) & Appearance & Drug content (\%) & & \multicolumn{2}{c}{ Release (\%) } \\
\hline 1 & no change & $98.67 \pm 0.73$ & SGF (2h) & SIF (4h) & SCF (24h) \\
2 & no change & $98.21 \pm 0.35$ & - & $3.83 \pm 0.05$ & $92.35 \pm 0.78$ \\
3 & no change & $98.32 \pm 0.48$ & - & $2.98 \pm 0.07$ & $91.88 \pm 0.54$ \\
6 & no change & $97.72 \pm 0.69$ & - & $3.32 \pm 0.06$ & $92.12 \pm 0.69$ \\
\hline
\end{tabular}




\section{CONCLUSION}

We have designed a new microbially triggered system based on chitosan for colonic drug delivery. The characteristics of the designed complex film depend on the chitosan/gelatin blend ratio; a 6:4 blend ratio was optimal. The Eudragit and chitosan/gelatin bilayer coating system prevented drug release in SGF and SIF. The drug was almost completely released in SCF after $24 \mathrm{~h}$. Colontargeted drug delivery was achieved by using a chitosan/ gelatin complex film and a multilayer coating system.

\section{ACKNOWLEDGEMENTS}

Our study was supported by the Wu Liande Fund for the Youth of Harbin Medical University (WLD-QN1111) and Harbin Medical University Scientific Research Innovation Fund No 2016LCZX68.

\section{REFERENCES}

BERGO, P.; SOBRAL, P.J.A. Effects of plasticizer on physical properties of pigskin gelatin films. Food Hydrocoll., v.21, p.1285-1289, 2007.

BHATTARAI, N.; GUNN, J.; ZHANG, M. Chitosan-based hydrogels for controlled, localized drug delivery. Adv. Drug Deliv. Rev., v.62, n.1, p.83-99, 2010.

CAO, N.; FU, Y.; HE, J. Preparation and physical properties of soy protein isolate and gelatin composite films. Food Hydrocoll., v.21, p.1153-1162, 2007.

CELA S C O, G.; M OR O, L.; B OZZELLA, R.; MANGANANGANO, K.; QUATTROCCHI, C.; AIELLO, C.; DONIA, M.; FAGONE, P.; DI MARCO, R. Efficacy of intracolonic administration of low-molecular-weight heparin CB-01-05, compared to other low-molecular-weight heparins and unfractionated heparin, in experimentally induced colitis in rat. Dig. Dis. Sci., v.53, n.12, p.31703175, 2008.

CHOURASIA, M.K.; JAIN, S.K. Pharmaceutical approaches to colon targeted drug delivery systems. J. Pharm. Pharm. Sci., v.6, n.1, p.33-66, 2003.
CHOURASIA, M.K.; JAIN, S.K. Polysaccharides for colon targeted drug delivery. Drug Deliv., v.11, n.2, p.129-148, 2004.

CUI, F.D.; JIE, J.; LI, W.; HONGZE, P.; WENHUI, L.; DONGMEI, C. Preparation and in vitro evaluation of $\mathrm{pH}$, time-based and enzyme-degradable pellets for colonic drug delivery. Drug Dev. Ind. Pharm., v.33, n.9, p.999-1007, 2007.

CUMMINGS, J.H.; MACFARLANE, G.T. The control and consequences of bacterial fermentation in the human colon. J. Appl. Bacteriol., v.70, n.6, p.443-459, 1991.

DEV, R.K.; BALI, V.; PATHAK, K. Novel microbially triggered colon specific delivery system of 5-Fluorouracil: Statistical optimization, in vitro, in vivo, cytotoxic and stability assessment. Int. J. Pharm., v.411, n.1-2, p.142-151, 2011.

DHANESHWAR, S.S.; GAIROLA, N.; KANDPAL, M.; VADNERKAR, G.; BHATT, L. Colon-specific, mutual azo prodrug of 5-aminosalicylic acid with L-tryptophan: synthesis, kinetic studies and evaluation of its mitigating effect in trinitrobenzenesulfonic acid-induced colitis in rats. Bioorg. Med. Chem., v.15, n.14, p.4903-4909, 2007.

DI PIERRO, P.; CHICO, B.; VILLALONGA, R.; MARINIELLO, L.; DAMIAO, A.E.; MASI, P.; PORTA, R. Chitosan-whey protein edible films produced in the absence or presence of transglutaminase: analysis of their mechanical and barrier properties. Biomacromolecules. v.7, n.3, p.744-749, 2006.

ENGLYST, H.N.; CUMMINGS, J.H. Digestion of the polysaccharides of some cereal foods in the human small intestine. Am. J. Clin. Nutr., v.42, n.5, p.778-787, 1985.

FAN, L.F.; HE, W.; CHANG, Y.Z.; XIANG, B.; DU, Q.; WANG, F.; QIN, M.; CAO, D.Y. Studies of chitosan/Kollicoat SR 30D film-coated tablets for colonic drug delivery. Int. $J$. Pharm., v.375, n.1-2, p.8-15, 2009.

FINEGOLD, S.M.; SUTTER, V.L.; SUGIHARA, P.T.; ELDER, H.A.; LEHMANN, S.M.; PHILLIPS, R.L. Fecal microbial flora in Seventh Day Adventist populations and control subjects. Am. J. Clin. Nutr., v.30, n.11, p.1781-1792, 1977. 
GAMELIN, E.; BOISDRON-CELLE, M.; DELVA, R.; REGIMBEAU, C.; CAILLEUX, P.E.; ALLEAUME, C.; MAILLET, M.L.; GOUDIER, M.J.; SIRE, M.; PERSONJOLY, M.C.; MAIGRE, M.; MAILLART, P.; FETY, R.; BURTIN, P.; LORTHOLARY, A.; DUMESNIL, Y.; PICON, L.; GESLIN, J.; GESTA, P.; DANQUECHINDORVAL, E.; LARRA, F.; Robert, J. Long-term weekly treatment of colorectal metastatic cancer with fluorouracil and leucovorin: results of a multicentric prospective trial of fluorouracil dosage optimization by pharmacokinetic monitoring in 152 patients. J. Clin. Oncol., v. 16, n.4, p.1470-1478, 1998.

GHAFFARI, A.; NAVAEE, K.; OSKOUI, M.; BAYATI, K.; RAFIEE-TEHRANI, M. Preparation and characterization of free mixed-film of pectin/chitosan/Eudragit RS intended for sigmoidal drug delivery. Eur. J. Pharm. Biopharm., v.67, n.1, p.175-186, 2007.

GUARNER, F.; MALAGELADA, J.R. Gut flora in health and disease. Lancet, v.361, n.9356, p.512-519, 2003.

GUPTA, V.K.; BECKERT, T.E.; PRICE, J.C. A novel pH- and time-based multi-unit potential colonic drug delivery system. I. Development. Int. J. Pharm., v.213, p.83-91, n, 1-2, 2001.

JAIN, S.K.; JAIN, A. Target-specific drug release to the colon. Expert. Opin. Drug Deliv., v.5, n.5, p.483-498, 2008.

JOSE, S.; PREMA, M.T.; CHACKO, A.J.; THOMAS, A.C.; SOUTO, E. Colon specific chitosan microspheres for chronotherapy of chronic stable angina. Colloids. Surf. B. Biointerfaces., v.83, n.2, p.277-283, 2011. (There is no citation linked with this reference in the text. Verify, please!!)

LIU, H.; YANG, X.; NIE, S.F.; WEI, L.L.; ZHOU, L.L.; LIU, H.; TANG, R.; PAN, W.S. Chitosan-based controlled porosity osmotic pump for colon-specific delivery system: screening of formulation variables and in vitro investigation. Int. J. Pharm., v.332, n.1/2, p.115-124, 2007.

LORENZO-LAMOSA, M.L.; REMUNAN-LOPEZ, C.; VILAJATO, J.L.; ALONSO, M.J. Design of microencapsulated chitosan microspheres for colonic drug delivery. J. Control. Release, v.52, n.1/2, p.109-118, 1998.
LUO, J.; ZHONG, Y.; CAO, J.; CUI, H. Efficacy of oral colonspecific delivery capsule of low-molecular-weight heparin on ulcerative colitis. Biomed. Pharmacother., v.65, n.2, p.111-117, 2011.

MANO, J.F.; SILVA, G.A.; AZEVEDO, H.S.; MALAFAYA, P.B.; SOUSA, R.A.; SILVA, S.S.; BOESEL, L.F.; OLIVEIRA, J.M.; SANTOS, T.C.; MARQUES, A.P.; NEVES, N.M.; REIS, R.L. Natural origin biodegradable systems in tissue engineering and regenerative medicine: present status and some moving trends. J. R. Soc. Interface, v.4, n.17, p.999-1030, 2007.

MANSUR, H.S.; ORÉFICE, R.L.; MANSUR, A.A.P. Characterization of poly(vinyl alcohol)/poly(ethylene glycol) hydrogels and PVA-derived hybrids by small-angle X-ray scattering and FTIR spectroscopy. Polymer, v.45, p.7193-7202, 2004

MCCONNELL, E.L.; MURDAN, S.; BASIT, A.W. An investigation into the digestion of chitosan (noncrosslinked and crosslinked) by human colonic bacteria. J. Pharm. Sci., v.97, n.9, p.3820-3829, 2008.

MUZZARELLI, R.A. Biomedical exploitation of chitin and chitosan via mechano-chemical disassembly, electrospinning, dissolution in imidazolium ionic liquids, and supercritical drying. Mar. Drugs, v.9, n.9, p.1510-1533, 2011.

NATH, B.; NATH, L.K. Studies on stercuia gum formulations in the form of osmotic core tablet for colon-specific drug delivery of azathioprine. PDA J. Pharm. Sci. Technol., v.67, n.2, p.172-184, 2013.

NAGENDRA, R.; ROOPA, S.P.; GURINDER, S. Design and optimization of novel in situ gel of mercaptopurine for sustained drug delivery. Braz. J. Pharm. Sci., v.50, n.2, p.107-119, 2014.

PARK, J.H.; SARAVANAKUMAR, G.; KIM, K.; KWON, I.C. Targeted delivery of low molecular drugs using chitosan and its derivatives. Adv. Drug. Deliv. Rev., v.62, n.1, p.2841,2010

PINOTTI, A.; GARCÍA, M.A.; MARTINO, M.N.; ZARITZKY, N.E. Study on microstructure and physical properties of composite films based on chitosan and methylcellulose. Food Hydrocoll., v.21, n.1, p.66-72, 2007. 
PRODPRAN, T.; BENJAKUL, S.; ARTHARN, A. Properties and microstructure of protein-based film from round scad (Decapterus maruadsi) muscle as affected by palm oil and chitosan incorporation. Int. J. Biol. Macromol., v.41, n.5, p.605-610, 2007.

RUBINSTEIN, A. Approaches and opportunities in colonspecific drug delivery. Crit. Rev. Ther. Drug Carrier Syst., v.12, n.2-3, p.101-149, 1995.

RUEDA, D.R.; SECALL, T.; BAYER, R.K. Differences in the interaction of water with starch and chitosan films as revealed by infrared spectroscopy and differential scanning calorimetry. Carbohyd. Polym., v.40, n.1, p.49-56, 1999.

SALYERS, A.A.; LEEDLE, J.A. Carbohydrate metabolism in the human colon. In: HENTGES, D.J. (ed.). Human intestinal microflora in health and disease. New York: Academic Press, 1983. p.129-146.

SEBTI, I.; CHOLlet, E.; DEGRAEVE, P.; NOEL, C.; PEYROL, E. Water sensitivity, antimicrobial, and physicochemical analyses of edible films based on HPMC and/or chitosan. J. Agric. Food Chem., v.55, n.3, p.693699, 2007.

SINGLA, A.K.; CHAWLA, M. Chitosan: some pharmaceutical and biological aspects-an update. J. Pharm. Pharmacol., v.53, n.8, p.1047-1067, 2001.

TOZAKI, H.; ODORIBA, T.; OKADA, N.; FUJITA, T.; TERABE, A.; SUZUKI, T.; OKABE, S.; MURANISHI, S.; YAMAMOTO, A. Chitosan capsules for colon-specific drug delivery: enhanced localization of 5-aminosalicylic acid in the large intestine accelerates healing of TNBS-induced colitis in rats. J. Control. Release, v.82, n.1, p.51-61, 2002.
VAGHANI, S.S.; PATEL, M.M.; SATISH, C.S. Synthesis and characterization of $\mathrm{pH}$-sensitive hydrogel composed of carboxymethyl chitosan for colon targeted delivery of ornidazole. Carbohydr. Res., v.347, n.1, p.76-82, 2012.

VARGAS, M.; ALBORS, A.; CHIRALT, A.; GONZÁLEZMARTÍNEZ, C. Characterization of chitosan-oleic acid composite films. Food Hydrocoll., v. 23, n.2, p.536-547, 2009.

YANG, L. Biorelevant dissolution testing of colon-specific delivery systems activated by colonic microflora. J. Control. Release, v.125, n.2, p.77-86, 2008.

YIN, H.Q.; LEE, E.S.; KIM, D.; LEE, K.H.; OH, K.T.; BAE, Y.H. Physicochemical characteristics of $\mathrm{pH}$-sensitive poly(L-Histidine)-b-poly (ethylene glycol)/poly(LLactide)-b-poly(ethylene glycol) mixed micelles. $J$. Control. Release, v.126, n.2, p.130-138, 2008.

YU, Q.; SONG, Y.; SHI, X.; XU, C.; BIN, Y. Preparation and properties of chitosan derivative/poly(vinyl alcohol) blend film crosslinked with glutaraldehyde. Carbohyd. Polym., v.84, n.1, p.465-470, 2011

ZAMBITO, Y.; DI COLO, G. Preparation and in vitro evaluation of chitosan matrices for colonic controlled drug delivery. $J$. Pharm. Pharm. Sci., v.6, n.2, p.274-281, 2003.

ZHANG, H.; ALSARRA, I.A.; NEAU, S.H. An in vitro evaluation of a chitosan-containing multiparticulate system for macromolecule delivery to the colon. Int. J. Pharm., v.239, n.1/2, p.197-205, 2002.

Received for publication on $15^{\text {th }}$ January 2015 Accepted for publication on $24^{\text {th }}$ October 2016 